\title{
Evaluation of IMERG-E Precipitation Estimates for Fire Weather Applications in Alaska
}

\author{
TAYLOR A. GOWAN AND JOHN D. HOREL \\ Department of Atmospheric Sciences, University of Utah, Salt Lake City, Utah
}

(Manuscript received 6 February 2020, in final form 22 May 2020)

\begin{abstract}
Large wildfire outbreaks in Alaska are common from June to August. The Canadian Forest Fire Danger Rating System (CFFDRS) is used operationally by Alaskan fire managers to produce statewide fire weather outlooks and forecast guidance near active wildfires. The CFFDRS estimates of fire potential and behavior rely heavily on meteorological observations (precipitation, temperature, wind speed, and relative humidity) from the relatively small number of in situ stations across Alaska with precipitation being the most critical parameter. To improve the spatial coverage of precipitation estimates across Alaska for fire weather applications, a multisatellite precipitation algorithm was evaluated during six fire seasons (1 June31 August 2014-19). Near-real-time daily precipitation estimates from the Integrated Multisatellite Retrievals for the Global Precipitation Mission (IMERG) algorithm were verified using 322 in situ stations across four Alaskan regions. For each region, empirical cumulative distributions of daily precipitation were obtained from station observations during each summer, and compared to corresponding distributions of interpolated values from IMERG grid points $\left(0.1^{\circ} \times 0.1^{\circ}\right.$ grid $)$. The cumulative distributions obtained from IMERG exhibited wet biases relative to the observed distributions for all regions, precipitation amount ranges, and summers. A bias correction approach using regional quantile mapping was developed to mitigate for the IMERG wet bias. The bias-adjusted IMERG daily precipitation estimates were then evaluated and found to produce improved gridded IMERG precipitation estimates. This approach may help to improve situational awareness of wildfire potential across Alaska and be appropriate for other highlatitude regions where there are sufficient in situ precipitation observations to help correct the IMERG precipitation estimates.
\end{abstract}

\section{Introduction}

Wildfire outbreaks are common in Alaska's dense boreal forests during the summer months when daylight can persist for more than $20 \mathrm{~h}$ each day, surface heating is maximized, and convection is frequent (Shulski and Wendler 2007; Bieniek et al. 2014; Melvin et al. 2017; Pickell et al. 2017). In recent decades, wildfire outbreaks have become more numerous, especially in Alaska's interior. In total, 5 of the 10 largest fire seasons in terms of acres burned have occurred after 2000. The flammability of fuels, number of ignitions, and total area burned are largely dependent on natural, rather than anthropogenic, factors (e.g., frequency of convection and lightning and subseasonal to seasonal precipitation and temperature patterns) (Ziel et al. 2015; Pickell et al. 2017). Thus, it is critical to have accurate

Corresponding author: Taylor A. Gowan, taylor.mccorkle@ utah.edu atmospheric data for operational products that are used for situational awareness before and during wildfire outbreaks.

The Alaska Interagency Coordination Center (AICC) is tasked with managing the resources for suppressing wildfires. The AICC staff evaluate fuel conditions and wildfire potential in part on the basis of the Canadian Forest Fire Danger Rating System (CFFDRS; Lawson and Armitage 2008). The CFFDRS depends on the assumed initial fuel state at the beginning of the fire season and continuous daily inputs, many of which are meteorological observations (rainfall, temperature, wind, and moisture), thereafter to calculate indices of fuel conditions and flammability (De Groot et al. 2003; Flannigan et al. 2013; Horel et al. 2014; Field et al. 2015). The CFFDRS indices are calculated each day and made available publicly as part of the Alaska Fire and Fuels program that is supported by the AICC (see http:// akff.mesowest.org). Meteorological inputs are obtained at in situ sites from selected observational networks and 
in gridded form at $2.5-\mathrm{km}$ horizontal resolution for precipitation from the Alaska-Pacific River Forecast Center (APRFC) and for temperature, wind, and relative humidity from Real Time Mesoscale Analyses (De Pondeca et al. 2011). The APRFC quantitative precipitation estimate (QPE) grids are derived by adjusting the precipitation at the widely scattered observing sites by monthly gridded climatological fields and terrainprecipitation relationships. Given the inherent range of temporal and spatial scales of summer rainfall in Alaska, the in situ data available across Alaska are likely unrepresentative of the rainfall variability within the state. The resulting potential inaccuracies in the daily precipitation estimates require fire behavior analysts to spend additional time evaluating whether the calculated CFFDRS index values reflect the actual conditions.

One of the fundamental CFFDRS indices, Fine Fuel Moisture Code (FFMC), estimates the flammability of grasses and other fine fuels and is highly sensitive to the precipitation from the previous day. High values of FFMC correspond to dry fine fuels (Lawson and Armitage 2008). Figure 1 illustrates the impact of a midsummer storm that shifted from southwest Alaska on 21 June 2018 to central Alaska the next day. The high values of FFMC on 21 June 2018 in central Alaska (Fig. 1b) computed using the APRFC QPEs dropped substantially over the next $24 \mathrm{~h}$ (Fig. 1d). This example obtained from the operational Alaska Fire and Fuels grids illustrates that reliable fire danger indices require accurate estimates of the amount and spatial distribution of precipitation.

Few regions of the world have sufficient in situ precipitation observations or radar coverage to monitor the complex spatial and temporal variations in precipitation around the globe (Huffman et al. 2001, 2007; Kirstetter et al. 2014; Asong et al. 2017; Kidd et al. 2017; Skofronick-Jackson et al. 2017; Lundquist et al. 2019). Satellite-derived precipitation from the joint U.S.-Japan Global Precipitation Measurement (GPM) mission (Hou et al. 2014) is an approach to monitor precipitation globally, which is particularly relevant for the types of natural disasters that occur within the 1.718 million $\mathrm{km}^{2}$ area of Alaska (Shulski and Wendler 2007; Bieniek et al. 2012, 2014; Lader et al. 2017). Precipitation datasets are now available every half hour from the Integrated Multisatellite Retrievals for the GPM (IMERG). Since the mission's launch in 2014, extensive evaluations of IMERG precipitation estimates have been conducted in the Netherlands (Gaona et al. 2016), southeast Austria (Sungmin et al. 2017), Africa (Dezfuli et al. 2017), China (Tang et al. 2016; Tian et al. 2018), the northern highlands of Pakistan
(Anjum et al. 2018), the Peruvian-Ecuadorian Amazon basin (Zubieta et al. 2017), and in Iran's regions of complex terrain (Sharafi et al. 2016). Additionally, IMERG has been used as a validation dataset for verifying global forecasts of precipitation (Kotsuki et al. 2019) as well as modeled precipitation in extratropical cyclones (Naud et al. 2020). This study aims to be the first detailed evaluation of IMERG precipitation at latitudes poleward of $60^{\circ} \mathrm{N} / \mathrm{S}$.

The objective of this research is to evaluate and improve the utility of the Early (4-h latency) IMERG QPEs, which have the greatest potential for operational applications in Alaska. The 24-h (h) accumulations (0000-0000 UTC) of IMERG precipitation are examined across Alaska during the 2014-19 fire seasons (defined here as 1 June-31 August). In situ rainfall data are used to evaluate and bias-correct the IMERG QPEs and thereby create estimates of gridded daily precipitation in addition to that presently available from the APRFC. Our approach builds upon prior precipitation evaluation and bias correction studies that have used regional or quantile-based approaches (Erickson et al. 2012; Pierce et al. 2015; Nelson et al. 2016; Hashemi et al. 2017; Gowan et al. 2018). Our verification serves as a baseline for estimating the performance of IMERG in other high-latitude regions as well as its potential for fire weather applications at short lead times.

The remainder of this manuscript is structured as follows. Section 2 describes the IMERG algorithm and verification datasets while section 3 presents the methods used for evaluation and bias correction of the IMERG precipitation estimates. The quantitative verification results and the application of the bias correction techniques to the IMERG QPEs are presented in section 4 followed by a summary of the critical results and future work in section 5 .

\section{Precipitation datasets}

\section{a. IMERG algorithm}

The international GPM mission, a successor to the U.S.-Japan Tropical Rainfall Measurement Mission (TRMM; Liu et al. 2012), is advancing the global understanding of precipitation processes and improving the forecasting of extreme events that cause natural disasters (Hou et al. 2014). The GPM mission data products provide $0.1^{\circ} \times 0.1^{\circ}$ resolution precipitation estimates for all latitudes using the IMERG algorithm (GPM 2013; Hou et al. 2014; Skofronick-Jackson et al. 2017). The current version of IMERG, 06B (v6), includes precipitation estimates for all latitudes, which is 

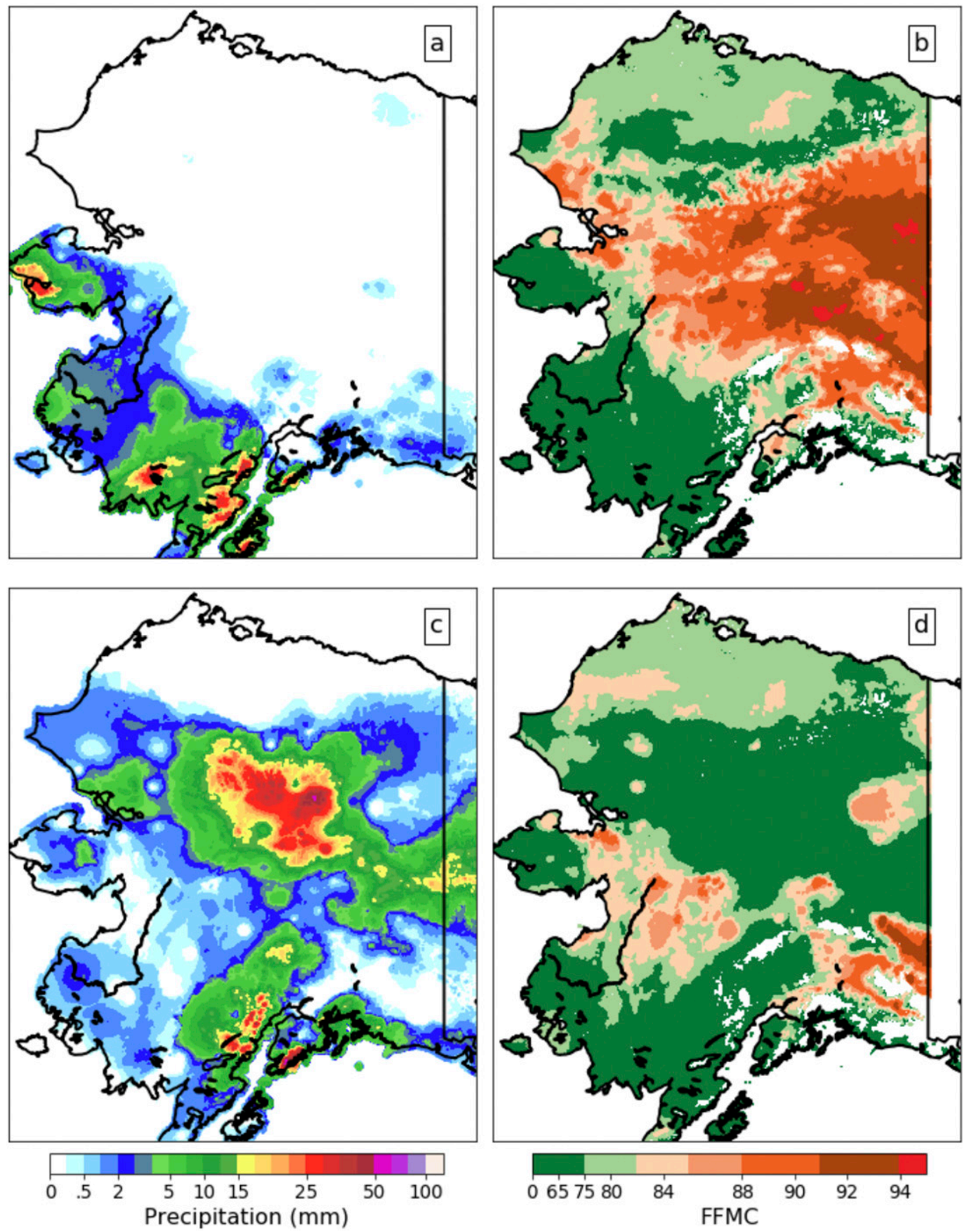

FIG. 1. (a) APRFC QPE (mm) valid for the 24-h period ending at 0000 UTC 22 Jun 2018, shaded according to the scale on the bottom left. (b) FFMC values valid at 2200 UTC 22 Jun 2018, shaded according to the scale on the bottom right. (c) As in (a), but valid for the $24 \mathrm{~h}$ period ending at 0000 UTC 23 Jun 2018. (d) As in (b), but valid at 2200 UTC 23 Jun 2018.

an improvement over the limited latitudinal domains of its predecessors, the TRMM Multisatellite Precipitation Analysis $\left(40^{\circ} \mathrm{S}-40^{\circ} \mathrm{N}\right)$, and earlier versions of IMERG $\left(60^{\circ} \mathrm{S}-60^{\circ} \mathrm{N}\right)$. With each new version of IMERG, the GPM and TRMM archives are backfilled by running the newest version of the algorithm retrospectively, allowing for consistent, comprehensive evaluation for each version.

The IMERG algorithm was developed to incorporate all microwave and infrared (IR) retrievals from sensors 
on board satellites in the GPM constellation into a single global precipitation estimate $\left(\mathrm{mm} \mathrm{h}^{-1}\right)$ every half hour (GPM ATBD 2019). For each time interval, the IMERG is run three times to produce independent datasets of estimated precipitation rate. These runs are referred to as Early (-E), Late (-L), and Final (-F) with latencies of $4 \mathrm{~h}, 14 \mathrm{~h}$, and $\sim 3.5$ months, respectively. For this research, IMERG-E estimates of 24-h accumulated precipitation are evaluated.

For each run of the IMERG algorithm, precipitation estimates are computed from passive microwave brightness temperature retrievals using the Goddard Profiling Algorithm. This step is followed by gridding the data and performing a calibration based on the GPM Combined Instrument's sensors. Poleward of $60^{\circ}$, the Combined Instrument is calibrated to values from the Global Precipitation Climatology Project (GPCP; Huffman et al. 1997), due to a known low bias of GPM algorithms at high latitude (G. Huffman 2019, personal communication). Additionally, GPM IR-based estimates from the Precipitation Estimation from Remotely Sensed Information using Artificial Neural Networks Cloud Classification System (PERSIANN-CCS; Hong et al. 2004) are recalibrated based on trailing threemonth matched estimates from the merged microwave field. According to the technical documents (GPM ATBD 2019), the PERSIANN-CCS IR estimates are sent along with the merged microwave field for morphing in the forward and backward direction via Lagrangian time interpolation and based on a sequence of morphing vectors. Unlike previous versions, IMERG v6 uses IR morphing vectors computed from the ModernEra Retrospective Analysis for Research and Applications, version 2, allowing time interpolation to occur poleward of $60^{\circ} \mathrm{N} / \mathrm{S}$. Prior to this algorithm update, only passive microwave radiances over snow/ice-free surfaces were used to calculate IMERG precipitation estimates at high latitudes (GPM ATBD 2019). An important difference between IMERG runs lies in the postprocessing step, when the precipitation estimates are calibrated using in situ stations. The IMERG-E dataset is calibrated using monthly climate normals provided by stations in the GPCP, whereas the researchgrade IMERG-F dataset is adjusted by monthly satellitegauge accumulations, which explains in part the longer production latency.

\section{b. In situ observations}

Ground-based verification and bias correction of IMERG-E daily (0000-0000 UTC) precipitation estimates during the 2014-19 fire seasons were performed using daily precipitation accumulation observations from 155 stations managed by the NWS and 167 Remote
Automated Weather Stations (RAWS). These networks complement one another for verification purposes as the NWS stations are situated near airports or in low-lying, populated areas (McCorkle et al. 2018) while the RAWS network is deployed for fire weather purposes typically in remote locations. These data were accessed and quality controlled by Synoptic Data, a Public Benefit Corporation (https://synopticdata.com), which provides access to environmental data from publicly available networks across all 50 states.

\section{Assessment of IMERG-E quantitative precipi- tation estimates}

\section{a. Quantitative evaluation methods}

The baseline accuracy of the IMERG-E dataset across Alaska is evaluated by comparing daily precipitation estimates during the 2014-19 fire seasons to in situ observations. To validate IMERG-E, we compared observations at each RAWS and NWS station to precipitation estimates at nearby IMERG-E grid points using bilinear interpolation. Our approach is intended to overcome common issues for precipitation verification in Alaska and elsewhere: 1) the limited number of in situ observing sites and 2) the wide range in precipitation amounts on daily time scales across the state. We first subset the in situ stations and IMERG grid values into quadrants demarcated by the latitude and longitude lines of $63^{\circ} \mathrm{N}$ and $152^{\circ} \mathrm{W}$. These quadrant boundaries were selected to roughly balance among the regions the available numbers of stations from the RAWS and NWS networks (Fig. 2).

As shown in Fig. 3, in situ observations of 24-h precipitation were aggregated within each region during all of the 2014-19 fire seasons to obtain climatological cumulative distribution functions (CDFs). Across Alaska, no rainfall is measured roughly $60 \%$ of the time while rainfall amounts in excess of $10 \mathrm{~mm} \mathrm{day}^{-1}$ occur less than $10 \%$ of the time (Fig. 3). These climatological CDFs helped define percentile regimes and regionspecific accumulation thresholds for the IMERG-E verification. In a similar manner, the IMERG-E QPEs interpolated to the observation sites during all six fire seasons were combined and transformed into climatological CDFs for the four regions (not shown).

For each region, the distribution of daily IMERG-E QPEs during the six fire seasons are evaluated with the equivalent distribution from RAWS and NWS in situ observations as a function of time, region, and event magnitude. Several error metrics are used: frequency bias, bias ratio, mean absolute error (MAE), and rootmean-square error (RMSE). 


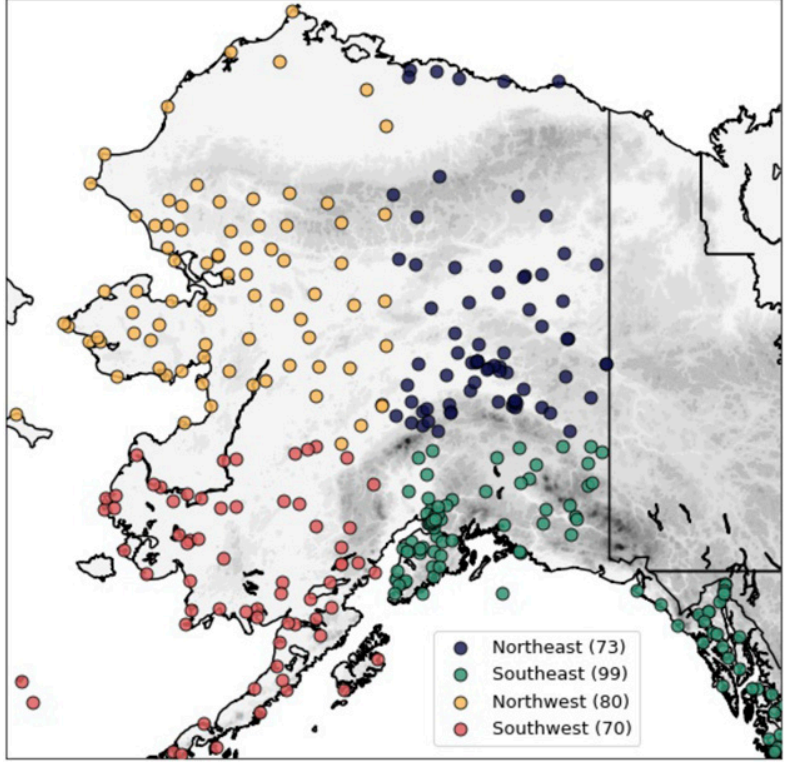

FIG. 2. In situ stations used for the IMERG-E evaluation. Station locations within the four regions are colored according to the legend with the total number of stations available in each region listed in the legend.

Frequency bias and bias ratio highlight the satellite's tendency to over or underestimate the detection and representation of an event of a given size. These metrics are defined as

$$
\text { frequency bias }=\frac{N_{s}}{N_{o}}, \quad \text { bias ratio }=\frac{\sum_{i=1}^{n} S_{i}}{\sum_{i=1}^{n} O_{i}},
$$

where $N_{s}\left(N_{o}\right)$ is the number of times IMERG-E (in situ station) detected (observed) an event of a given magnitude and $S_{i}\left(O_{i}\right)$ is the IMERG-E estimate (in situ observation) of precipitation at each grid point (station location) $i$, with $n$ being the total number of locations. For both the frequency bias and the bias ratio, values near 1 imply that IMERG-E agrees well with the observations, while values less (greater) than 1 indicate an IMERG-E underestimate (overestimate).

The MAE and RMSE are additional metrics used to assess the overall agreement between the IMERG-E values and in situ observations:

$$
\mathrm{MAE}=\frac{1}{n} \sum_{i=1}^{n}\left|S_{i}-O_{i}\right|, \quad \mathrm{RMSE}=\sqrt{\frac{1}{n}\left(\sum_{i=1}^{n}\left(S_{i}-O_{i}\right)^{2}\right)} .
$$

Both the MAE and RMSE tend to be more sensitive to large errors arising from the occasional extremely large values of rainfall.

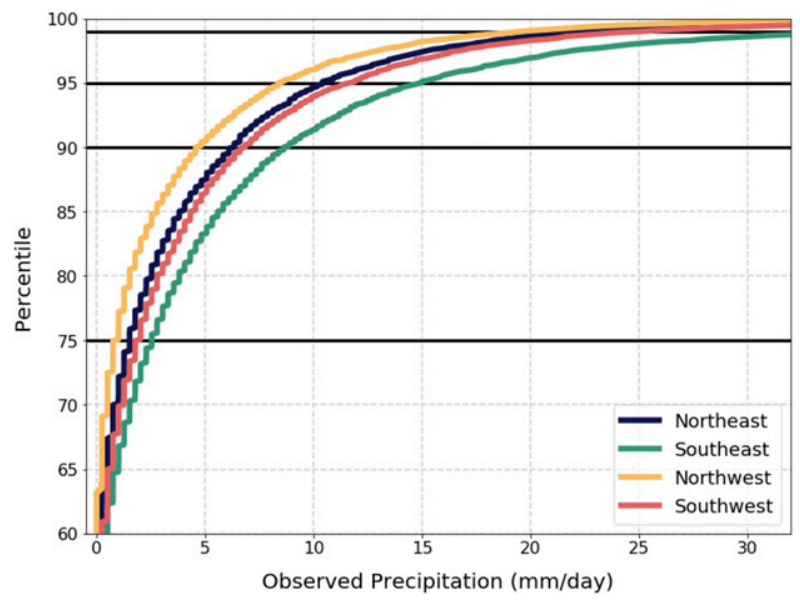

FIG. 3. Regional CDFs derived from daily precipitation observations during the six fire seasons from all stations in each region.

\section{b. Bias correction}

Globally, products that merge gauge data and satellitebased precipitation are often biased by unrepresentative and limited gauge data, particularly in mountains (Derin et al. 2016). This applies to the IMERG satellite-derived precipitation estimates, which are not expected to match in situ observations exactly since they are obtained from satellite-measured variables such as brightness temperature and other radiance quantities. Additionally, sensors have varied resolution across satellite platforms making it difficult to quantify uncertainty or even identify an error source when multiple sensors are inputs to a single algorithm, as is the case with IMERG (Bauer et al. 2011; Gebregiorgis et al. 2017). These problems appear exacerbated over regions of complex terrain or where in situ data are sparse. For these reasons, a bias correction technique is often used to mitigate for some of the uncertainties associated with satellite-derived precipitation estimate datasets.

We employ a simple bias correction method, hereafter referred to as regional quantile mapping, in order to improve the daily IMERG-E QPEs in a manner that could be used operationally. The regional aggregation of station and IMERG-E data is critical in order to avoid overfitting. The IMERG-E precipitation estimates at every grid point are bias corrected for each of the six summers independently, using the other five summers as a reference "climatology." The two steps are outlined here using a fictitious example for a specific grid point in the Northeast quadrant on 1 June 2014. We stipulate the IMERG-E estimated rainfall for that day and location was $5 \mathrm{~mm}$ :

1) A value of $5 \mathrm{~mm}$ in the Northeast quadrant in 2014 is found to correspond to the 85 th percentile for that 


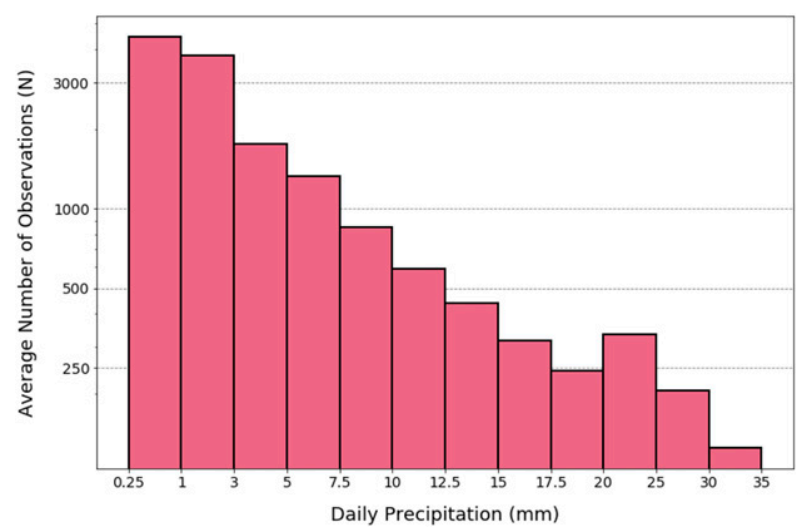

FIG. 4. Average number of daily precipitation observations across Alaska during the six fire seasons within the specified bin ranges.

quadrant based on all the IMERG-E values during the other 5 years (2015-19).

2) Since the 85th percentile for all in situ observations in the Northeast quadrant during the 2015-19 period is found to be $3 \mathrm{~mm}$, the quantile mapped (QM) IMERG-E value for 1 June 2014 at that grid point is then set to $3 \mathrm{~mm}$.

Using this technique, we bias correct the entire IMERG-E domain and evaluate those adjustments by comparing the independent observations available during each of the six summers to the gridpoint values near those locations (Hashemi et al. 2017). Limitations of this approach include the small discontinuities across the shared boundaries of the four regions arising from the CDF distributions computed for each separately. More serious limitations arise from the coarse resolution of the IMERG-E grid in mountainous regions within Alaska and when the observed conditions during the independent summer season differ substantially from those available in the dependent set of seasons used to derive the bias correction. These issues will be discussed later.

\section{Results}

\section{a. Verification of IMERG-E QPEs during the 2014-19 fire seasons}

During the Alaskan fire season, measurable precipitation occurs on approximately $40 \%$ of days (Fig. 3) with over 4000 of those observations in the $0.25-1.0 \mathrm{~mm}$ (0.01-0.04 in.) range, averaged over all years (Fig. 4). The frequency bias ratios within the specified precipitation ranges are shown in Fig. 5 for all stations during each of the six fire seasons. Since the regional variations

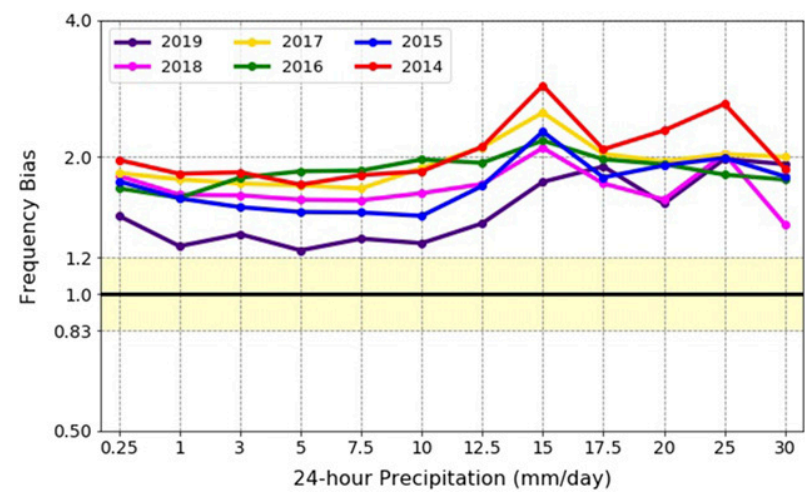

FIG. 5. IMERG-E frequency bias across Alaska as a function of daily observed precipitation $(\mathrm{mm})$ during each summer season and accumulated into the specified bin ranges (e.g., the values at 0.25 represent bias values corresponding to observed precipitation in the range $0.25-1.0 \mathrm{~mm}$ ). The shaded yellow region represents the acceptable range of frequency bias values $(0.83-1.20)$ defined in the text.

in the frequency bias ratio were small, only the aggregated statewide results are presented in Fig. 5. Following other precipitation verification studies (e.g., Lewis et al. 2017; Gowan et al. 2018), we highlight reasonable frequency bias values as those between 0.83 and 1.20. The counts of IMERG-E daily amounts were more than $20 \%$ higher than those observed (frequency bias ratios larger than 1.20) during all years and within all magnitude ranges. For the $\sim 200 \mathrm{ob}-$ served events over $15 \mathrm{~mm}$ that occur on average each season (Fig. 4), the counts of IMERG-E precipitation amounts were more than $50 \%$ higher than those observed (Fig. 5).

Bias ratios calculated for each fire season, region, and specified CDF percentile ranges are shown in Fig. 6. IMERG-E consistently overestimates precipitation amounts in each region for all percentile ranges with the exception of the 2018 fire season in the Southeast region. Over the Northeast region, IMERG-E cumulative amounts were more than double those observed during all seasons for smaller rainfall amounts (60th-75th percentile range, $\sim 0-3 \mathrm{~mm}$ ) while the smallest bias ratios were found for large precipitation amounts in the Southeast region (95th-99th percentile range).

As should be expected, MAE and RMSE values are quite large for the highest percentile ranges (precipitation amounts) as shown in Figs. 7 and 8, respectively. During each fire season, the MAE and RMSE values are similar in magnitude, suggesting a consistent direction of the bias magnitude. The MAE and RMSE values for each fire season are consistently highest in the Northeast and Southeast regions as those are the regions with 

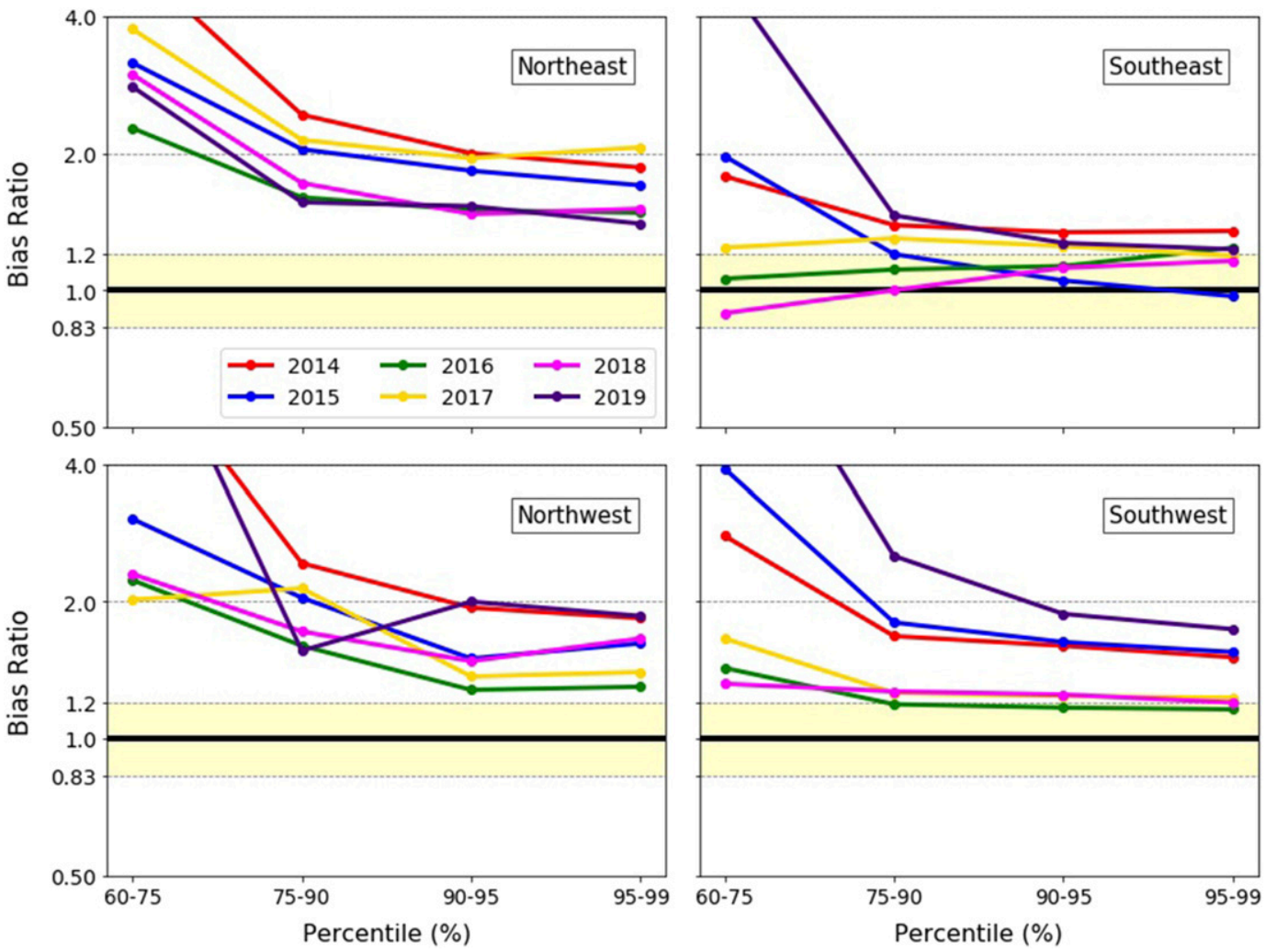

FIG. 6. Annual bias ratio as a function of region, fire season, and the observation's daily precipitation percentile (\%). The shaded yellow region represents the acceptable range of frequency bias values $(0.83-1.20)$ defined in the text.

higher climatological amounts of rainfall during the summer. For the Northwest and Southwest regions, the MAE (RMSE) values remain below $10 \mathrm{~mm}(15 \mathrm{~mm})$ for all percentile ranges, with the exception of the 2019 fire season, which was marked by several anomalous precipitation events, including an atmospheric river event that produced record-breaking rain across the state.

\section{b. Bias correction of IMERG-E precipitation estimates}

To mitigate for the IMERG-E systematic wet bias tendency and enhance objectively the overall usability of the satellite data for fire weather applications, we employ regional quantile mapping described in section 3 to create QM IMERG-E daily QPEs at each grid point for the 2014-19 fire seasons. Observed rainfall data during the fire season for which the IMERG-E data are being corrected are not used in the quantile mapping so that they can be used to evaluate the level of improvement obtained by this approach.

The IMERG-E QPEs before (Fig. 9a) and after (Fig. 9b) the regional quantile mapping for 22 June 2018 are compared to the APRFC QPEs for the same time period (Fig. 9c, previously shown in Fig. 1c). Since the QM IMERG-E QPEs were calculated only within the state of Alaska, no precipitation is shown in Canada in Fig. 9b. The reduction of the IMERG-E wet bias as a result of the regional quantile mapping is evident by comparing Figs. 9a and 9b. The overall precipitation patterns are generally similar between the IMERG-E and APRFC estimates. However, the APRFC analysis appears to miss the north-south band of precipitation west of the Alaska-Canada border, presumably because of the limited number of observing sites in that region (Fig. 2). The IMERG-E analyses do not show the higher precipitation amounts suggested by the APRFC QPEs in the southwest quadrant, which is difficult to verify as there are no stations in that region on this day reporting large rainfall amounts. That may result from the APRFC weighting heavily climatological values in that region.

To assess the potential improvement resulting from the bias correction, we evaluate the QM IMERG-E data using the same approaches applied previously to the IMERG-E data. For example, the substantial reduction 

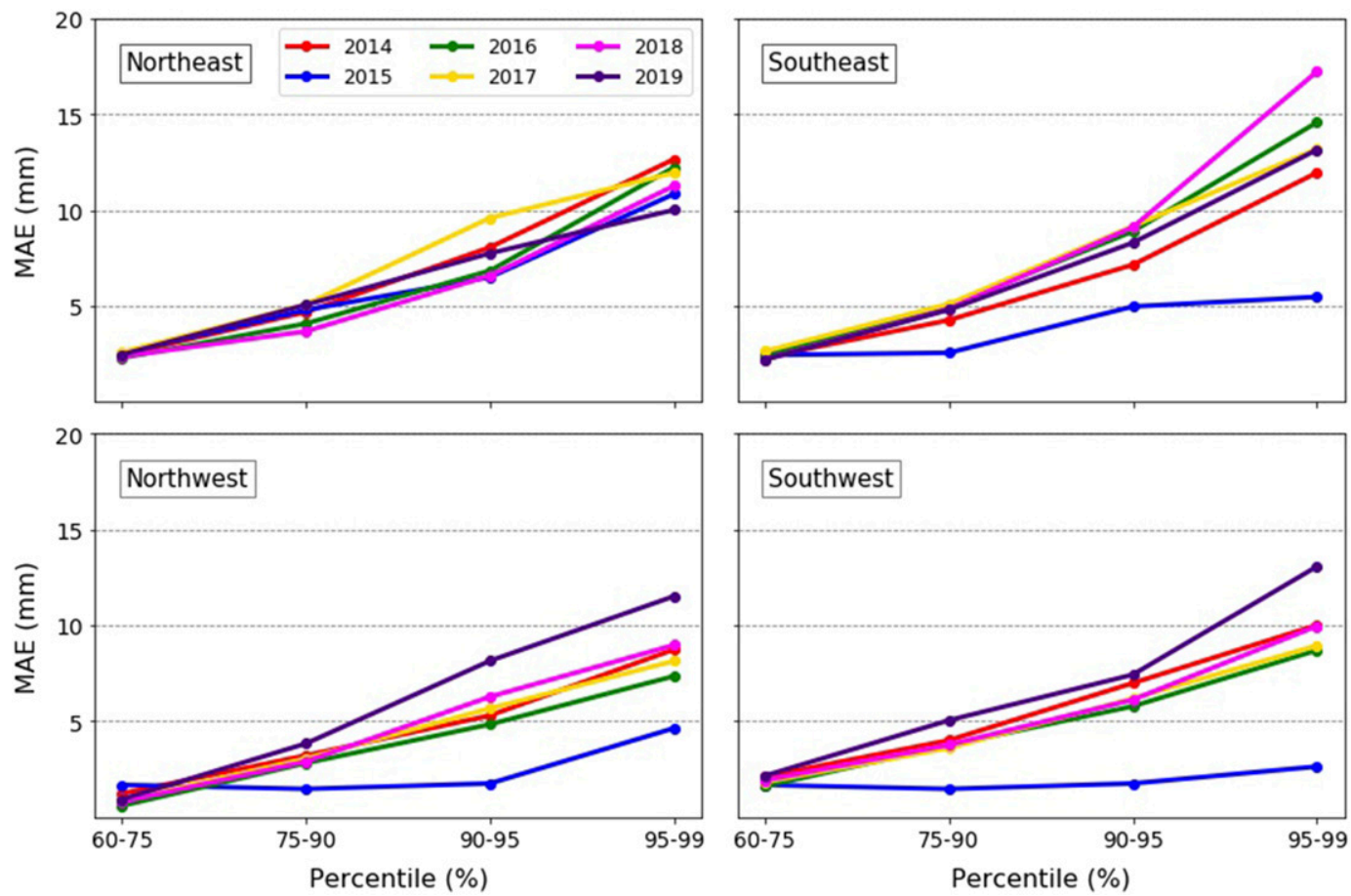

FIG. 7. MAE as a function of region, fire season, and the observation's daily precipitation accumulation percentile.

in the frequency biases for QM IMERG-E is evident for all precipitation amounts and fire seasons in Fig. 10 relative to those shown in Fig. 5 for IMERG-E. For some precipitation intervals and summer season, overestimates remain with a few cases where the QM IMERG-E now underestimates rainfall totals (e.g., for the largest precipitation amounts during 2019). Averaged over all six fire seasons, the QM IMERG-E frequency
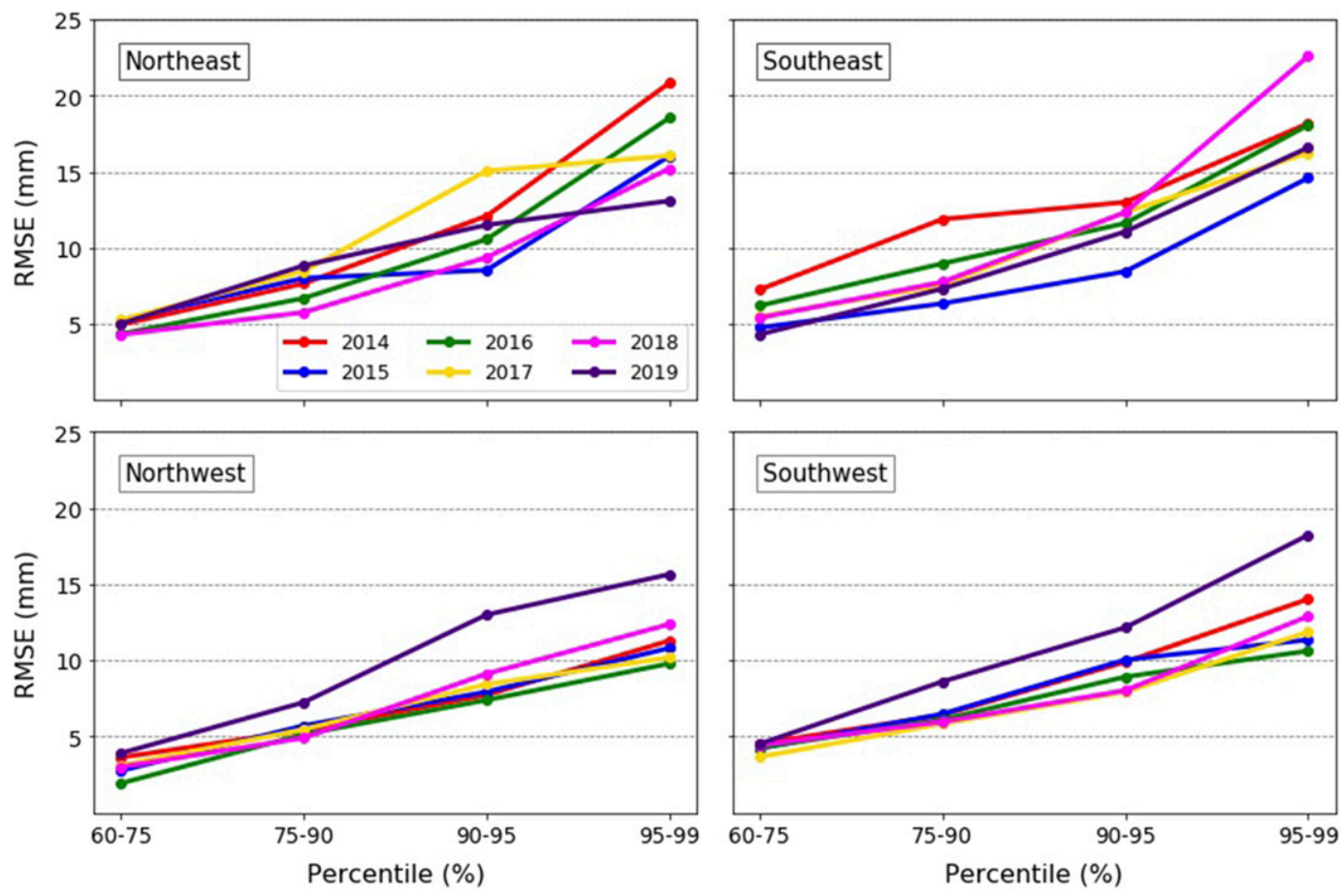

FIG. 8. As in Fig. 7, but for RMSE. 

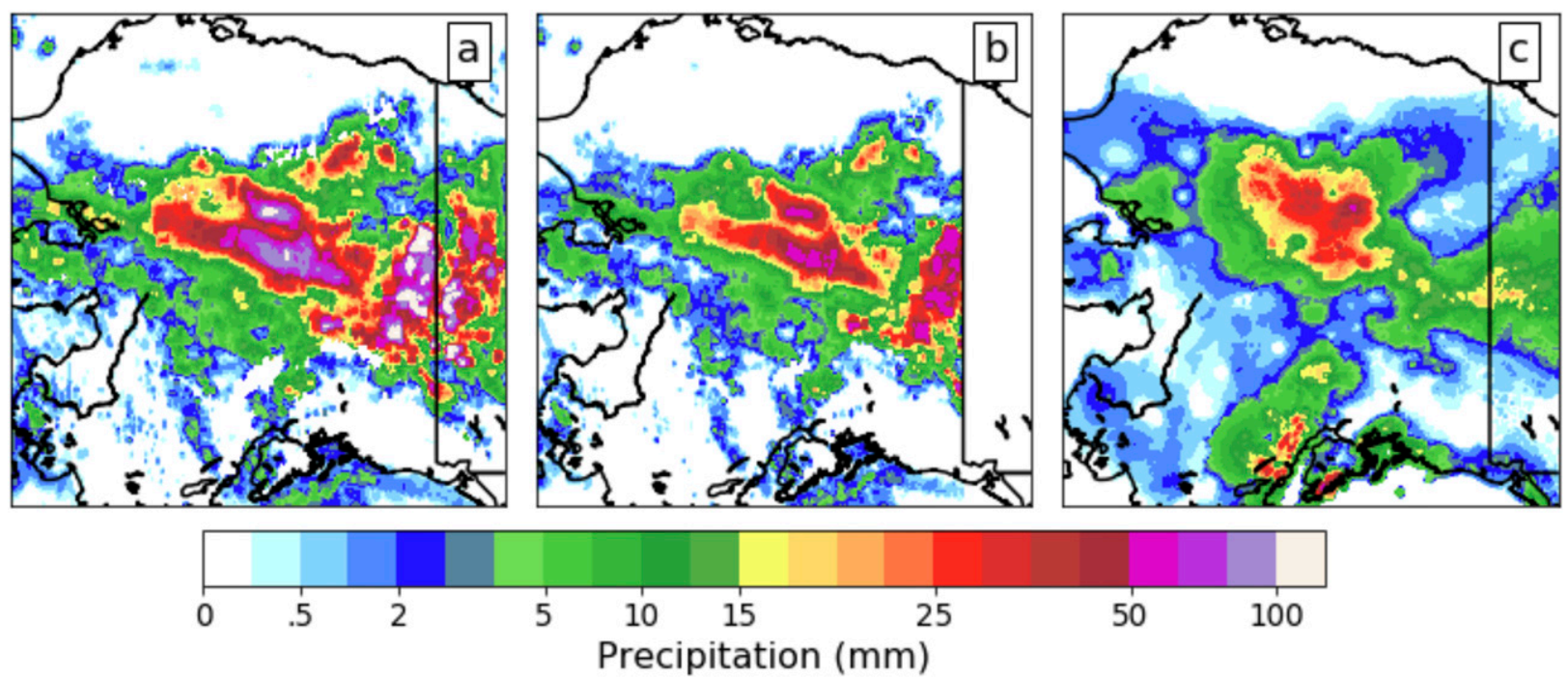

FIG. 9. 24-h precipitation estimates valid for 22 Jun 2018 shaded according to the scale below as derived by (a) IMERG-E, (b) QM IMERG-E, and (c) APRFC.

biases are improved for all regions from those obtained from IMERG-E.

Next, we discuss the QM IMERG-E bias ratios. Similar to the results from the frequency bias analysis, there was a substantial improvement in bias ratio score for all regions and percentile ranges. The improved bias ratios were similar for all regions and fire seasons (0.91-1.0), and thus are not shown graphically. The greatest percent improvement occurred for the Northeast and Northwest regions, which is encouraging from a fire weather standpoint given that many of the largest wildfires occur in these two regions. Additionally, the bias ratios for 60th-90th percentile ranges exhibit the largest percentage improvement from the baseline statistics for all regions. The average bias ratio values suggest that our bias correction method has been successful in accounting for and mitigating the wet bias that was originally present in the IMERG-E dataset.

We continue the evaluation of the QM IMERG-E precipitation estimates using the MAE (Fig. 11) and RMSE (Fig. 12) as a function of event percentile range and region. For the QM IMERG-E MAE, the most improvement occurred in the Northeast region for all percentile ranges, with the exception of the 60th-75th percentile regime. The average MAE slightly decreased in accuracy for Southeast and Southwest regions when evaluating $24-\mathrm{h}$ precipitation estimates within the 90th-99th percentile ranges. For the QM IMERG-E RMSE, all regions improved for all percentile ranges, with the exception of the Southeast region showing little change. The largest RMSE improvement occurred for the Northeast region for the 60th-75th and 75th-90th percentile ranges, respectively. While not all of the results yielded a net positive change, the largest improvements with the QM IMERG-E dataset occurred for the regions that are historically highly susceptible to wildfires.

As a final illustration of both the strengths and weaknesses of bias correction approaches, time series of accumulated precipitation observations from a RAWS station near Delta Junction (OKLA2) in the Northeast region and the Anchorage International Airport (PANC) in the Southeast region during the 2019 summer season are shown in Fig. 13. IMERG-E precipitation tracks the evolution of observed rainfall at OKLA2 throughout the summer (i.e., there are no extraneous rainfall events generated by the satellite algorithm). The excessive IMERG-E precipitation estimates were largely corrected at OKLA2 by the quantile mapping

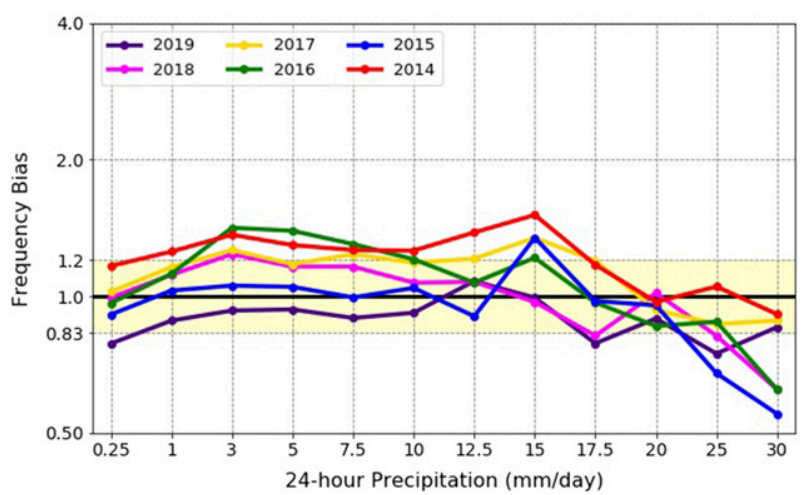

FIG. 10. As in Fig. 4, but for the QM IMERG-E dataset. 

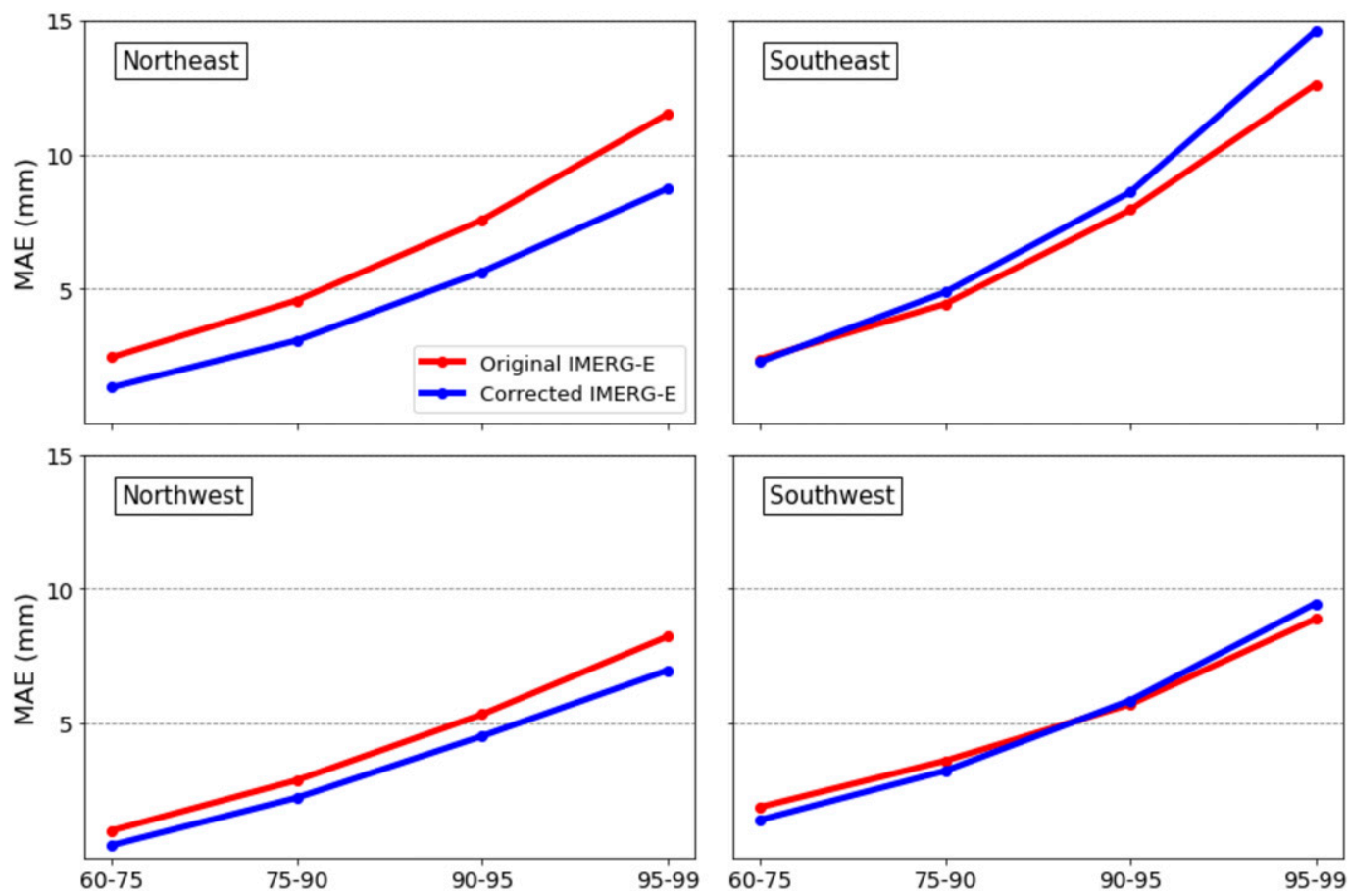

FIG. 11. Temporally averaged MAE for the IMERG-E (red line) and QM IMERG-E (blue line) as a function of region and the observation's daily precipitation accumulation percentile (\%).

and similar useful corrections were observed during the other five years (not shown).

The amplitude of the estimated rainfall at PANC during the late July 2019 rain event was far in excess of that observed (Fig. 13). Interpolating the $0.1^{\circ}(\sim 10 \mathrm{~km})$ resolution IMERG-E grid values to the PANC location may introduce representativeness errors, since the satellite estimates for the higher elevations in the nearby Chugach Mountains likely were larger than appropriate for PANC. The limited corrections to the IMERG-E estimates by the quantile mapping at PANC in this and the other summer seasons (not shown) are consistent with the limited changes in RMSE evident for the Southeast region during all seasons (Fig. 12).

\section{Summary and future work}

The IMERG-E QPEs are derived using retrievals from infrared and passive microwave sensors onboard multiple satellites. These retrievals are combined to create global snapshots of precipitation rates at a $0.1^{\circ}$ horizontal grid spacing every half hour. This research is the first evaluation of the IMERG-E QPEs at high latitudes and is geared toward assessing the algorithm's potential for use in fire weather applications, such as for input to calculate the CFFDRS fire weather indices.
We evaluated the IMERG-E estimates of daily precipitation totals during six fire seasons relative to observations from 322 in situ stations across Alaska. Given Alaska's immense size and varied climate regimes, we sectioned the state into four regions and verified IMERG-E using the corresponding stations within those regions separately during each of the six seasons. Climatological cumulative distribution functions were used to help identify how frequent daily rainfall totals were observed and estimated by IMERG-E.

The baseline verification revealed that the IMERG-E QPEs have a wet bias regardless of geographic region, year, or precipitation amount. More IMERG-E events were counted than observed and IMERG-E totals tended to be larger for all regions and event ranges than observed. The largest MAE and RMSE errors were found in the Northeast and Southeast regions of the state for all years and percentile regimes, which reflects in part the climatologically large amounts of summer rainfall in those areas. The results presented here may help to identify how the IMERG-E algorithm could be improved to reduce the wet bias of IMERG-E QPEs during summer.

Following the baseline verification, we bias-corrected the IMERG-E dataset using a regional quantile mapping approach, which was followed by seasonal cross 

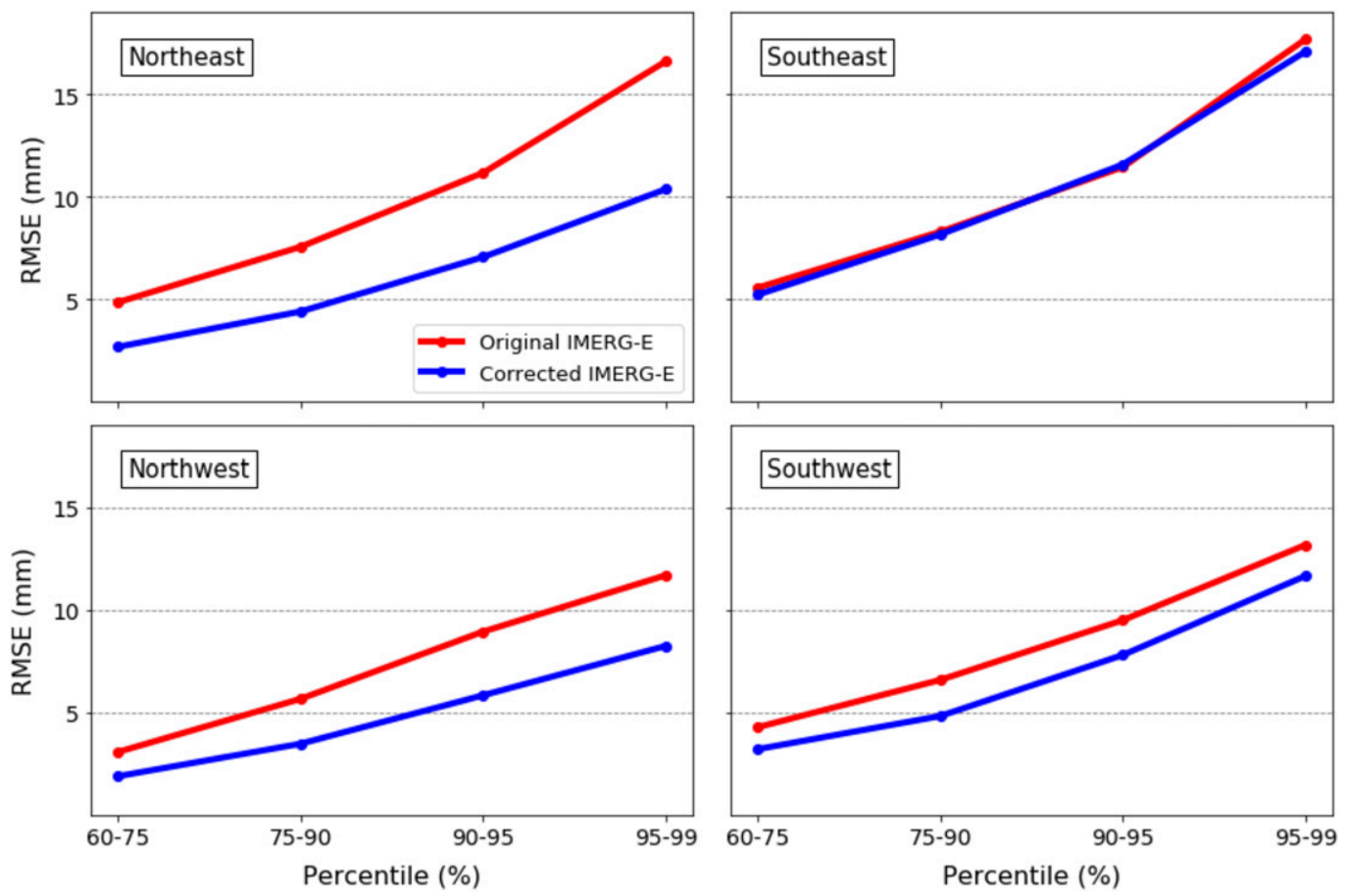

FIG. 12. As in Fig. 11, but for RMSE.

validation. The bias-corrected data were then evaluated in an identical manner to the original IMERG-E data. The bias correction yielded promising results:

1) The overall wet bias from the baseline verification was substantively reduced

2) Frequency bias and bias ratio scores fell to within acceptable ranges and approached unity for some regions and years

3) The greatest improvements in terms of MAE and RMSE were found in the Northeast and Northwest regions over all percentile ranges.

Bias correction adds value when the climatological range expected for the observed conditions is adequately sampled in space and time. As summarized by Lundquist et al. (2019), satellite-derived estimates of precipitation may not be the solution for accurately representing precipitation in complex terrain. Quantile mapping the satellite-derived estimates will also be less useful in the mountainous regions of Alaska since there are few observations available that are representative of conditions in those areas. The relatively coarse resolution of the IMERG-E grid also exacerbates such spatial representativeness concerns in regions of complex terrain. Changes over time in the types of satellite-derived products used in the IMERG-E algorithm could potentially affect the quantile mapping. However, a more serious issue is whether the observations aggregated within the region over a limited sample of years provide a sufficiently diverse climatology to reflect accurately what may happen during other summer seasons.

The IMERG-E QPEs are an invaluable resource for high-latitude locations such as Alaska where large swaths of the state have no automated precipitation observations. The quantile mapping approach was tested here by slicing Alaska into four arbitrary regions with roughly similar numbers of stations. The artificiality of the sector boundaries creates small discontinuities across the shared boundaries of the quadrants arising from the CDF distributions computed for each separately. This approach could be improved by adjusting the sectors to conform to regions with similar summer precipitation regimes, climate divisions, or the Predictive Service Areas define by the AICC.

IMERG-E QPE may be appropriate to use for computing fire potential and behavior indices in Alaska if its wet bias can be overcome. Further work is needed to assess what may be the minimum number of stations in the regions and number of summer seasons necessary to provide adequate samples for defining the observed regional CDFs on which the technique depends. Since the IMERG-E data are not available at high latitudes prior to 2014 , this approach may not be practical in other highlatitude regions where there are insufficient numbers of stations available during recent years. 

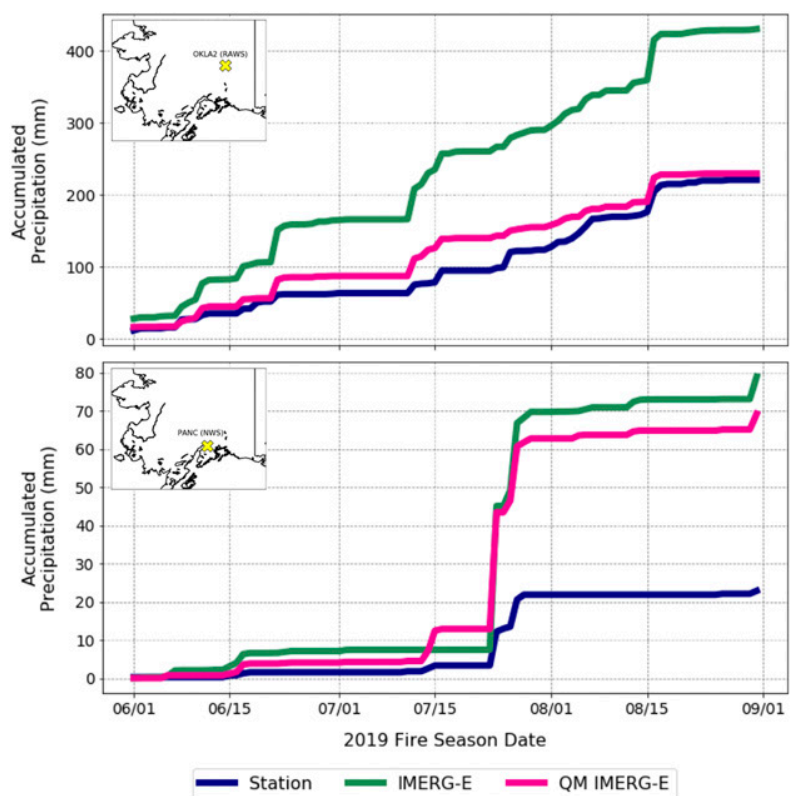

FIG. 13. Daily accumulated precipitation $(\mathrm{mm})$ for the 2019 fire season as estimated by in situ stations (blue line; station code, location, and network in upper-left corner of panels) and the corresponding IMERG-E and QM IMERG-E values (green and pink lines, respectively).

Acknowledgments. The authors thank George Huffman of the NASA Goddard Space Flight Center for generously using his time and GPM IMERG expertise to help make this study possible. The authors would also like to thank Robert Ziel, an Alaskan fire behavior analyst, who went above and beyond giving us his time and sharing his firsthand knowledge and experience throughout the duration of this study. This work was supported by the Joint Fire Science Program (JFSP Grant L17AC00225) and a Collaborative Science, Technology, and Applied Research (CSTAR) Program Award (55500146). Access to the IMERG data was provided by the NASA Precipitation Processing System and the Goddard Earth Sciences Data and Information Services Center. The University of Utah Center for High Performance Computing (CHPC) provided computational hardware and software.

\section{REFERENCES}

Anjum, M. N., Y. Ding, D. Shangguan, I. Ahmad, M. W. Ijaz, H. U. Farid, Y. E. Yagoub, and M. Adnan, 2018: Performance evaluation of latest integrated multi-satellite retrievals for global precipitation measurement (IMERG) over the northern highlands of Pakistan. Atmos. Res., 205, 134-146, https:// doi.org/10.1016/j.atmosres.2018.02.010.

Asong, Z. E., S. Razavi, H. S. Wheater, and J. S. Wong, 2017: Evaluation of Integrated Multisatellite Retrievals for GPM (IMERG) over southern Canada against ground precipitation observations: A preliminary assessment. J. Hydrometeor., 18, 1033-1050, https://doi.org/10.1175/JHM-D-16-0187.1.
Bauer, P., and Coauthors, 2011: Satellite cloud and precipitation assimilation at operational NWP centres. Quart. J. Roy. Meteor. Soc., 137, 1934-1951, https://doi.org/10.1002/qj.905.

Bieniek, P. A., and Coauthors, 2012: Climate divisions for Alaska based on objective methods. J. Appl. Meteor. Climatol., 51, 1276-1289, https://doi.org/10.1175/JAMC-D-11-0168.1.

_ J. E. Walsh, R. L. Thoman, and U. S. Bhatt, 2014: Using climate divisions to analyze variations and trends in Alaska temperature and precipitation. J. Climate, 27, 2800-2818, https://doi.org/10.1175/JCLI-D-13-00342.1.

De Groot, W. J., P. M. Bothwell, D. H. Carlsson, and K. A. Logan, 2003: Simulating the effects of future fire regimes on western Canadian boreal forests. J. Veg. Sci., 14, 355-364, https:// doi.org/10.1111/j.1654-1103.2003.tb02161.x.

De Pondeca, M. S., and Coauthors, 2011: The real-time mesoscale analysis at NOAA's National Centers for Environmental Prediction: Current status and development. Wea. Forecasting, 26, 593-612, https://doi.org/10.1175/WAF-D-10-05037.1.

Derin, Y., and Coauthors, 2016: Multiregional satellite precipitation products evaluations over complex terrain. J. Hydrometeor., 17, 1817-1836, https://doi.org/10.1175/JHM-D-15-0197.1.

Dezfuli, A. K., C. M. Ichoku, G. J. Huffman, K. I. Mohr, J. S. Selker, N. van de Giesen, R. Hochreutener, and F. O. Annor, 2017: Validation of IMERG precipitation in Africa. J. Hydrometeor., 18, 2817-2825, https://doi.org/10.1175/JHM-D-17-0139.1.

Erickson, M. J., B. A. Colle, and J. J. Charney, 2012: Impact of bias correction type and conditional training on Bayesian model averaging over the northeast United States. Wea. Forecasting, 27, 1449-1469, https://doi.org/10.1175/WAF-D-11-00149.1.

Field, R. D., and Coauthors, 2015: Development of a global fire weather database. Nat. Hazards Earth Syst. Sci., 15, 1407-1423, https://doi.org/10.5194/nhess-15-1407-2015.

Flannigan, M. D., A. S. Cantin, W. J. de Groot, M. Wotton, A. Newbery, and L. Gowman, 2013: Global wildland fire season severity in the 21st century. For. Ecol. Manage., 294, 54-61, https://doi.org/10.1016/j.foreco.2012.10.022.

Gaona, M. F. R., A. Overeem, H. Leijnse, and R. Uilenhoet, 2016: First-year evaluation of GPM rainfall over the Netherlands: IMERG day 1 final run (V03D). J. Hydrometeor., 17, 27992814, https://doi.org/10.1175/JHM-D-16-0087.1.

Gebregiorgis, A. S., P. Kirstetter, Y. E. Hong, N. J. Carr, J. J. Gourley, W. Petersen, and Y. Zheng, 2017: Understanding overland multisensor satellite precipitation error in TMPART products. J. Hydrometeor., 18, 285-306, https://doi.org/ 10.1175/JHM-D-15-0207.1.

Gowan, T. M., W. J. Steenburgh, and C. S. Schwartz, 2018: Validation of mountain precipitation forecasts from the convection-permitting NCAR ensemble and operational forecast systems over the western United States. Wea. Forecasting, 33, 739-765, https://doi.org/10.1175/WAF-D-17-0144.1.

GPM, 2013: Precipitation measurement missions. Global Precipitation Measurement Program, NASA, accessed 15 July 2019, http://gpm.nasa.gov/.

GPM ATBD, 2019: Global precipitation measurement algorithm theoretical basis documents. NASA, accessed 22 July 2019, https://pps.gsfc.nasa.gov/atbd.html.

Hashemi, H., M. Nordin, V. Lakshmi, G. J. Huffman, and R. Knight, 2017: Bias correction of long-term satellite monthly precipitation product (TRMM 3B43) over the conterminous United States. J. Hydrometeor., 18, 2491-2509, https://doi.org/ 10.1175/JHM-D-17-0025.1.

Hong, Y., K. Hsu, S. Sorooshian, and X. Gao, 2004: Precipitation estimation from remotely sensed imagery using an artificial 
neural network cloud classification system. J. Appl. Meteor., 43, 1834-1853, https://doi.org/10.1175/JAM2173.1.

Horel, J. D., R. Ziel, C. Galli, J. Pechmann, and X. Dong, 2014: An evaluation of fire danger and behaviour indices in the Great Lakes Region calculated from station and gridded weather information. Int. J. Wildland Fire, 23, 202-214, https://doi.org/ 10.1071/WF12186.

Hou, A. Y., and Coauthors, 2014: The Global Precipitation Measurement Mission. Bull. Amer. Meteor. Soc., 95, 701-722, https://doi.org/10.1175/BAMS-D-13-00164.1.

Huffman, G. J., and Coauthors, 1997: The Global Precipitation Climatology Project (GPCP) combined precipitation dataset. Bull. Amer. Meteor. Soc., 78, 5-20, https://doi.org/10.1175/ 1520-0477(1997)078<0005:TGPCPG > 2.0.CO;2.

— , R. F. Adler, M. M. Morrissey, D. T. Bolvin, S. Curtis, R. Joyce, B. McGavock, and J. Susskind, 2001: Global precipitation at one-degree daily resolution from multisatellite observations. J. Hydrometeor., 2, 36-50, https://doi.org/ 10.1175/1525-7541(2001)002<0036:GPAODD>2.0.CO;2.

- and Coauthors, 2007: The TRMM Multisatellite Precipitation Analysis (TMPA): Quasi-global, multiyear, combined-sensor precipitation estimates at fine scales. J. Hydrometeor., 8, 38-55, https://doi.org/10.1175/JHM560.1.

Kidd, C., A. Becker, G. J. Huffman, C. L. Muller, P. Joe, G. Skofronick-Jackson, and D. B. Kirschbaum, 2017: So, how much of the Earth's surface is covered by rain gauges? Bull. Amer. Meteor. Soc., 98, 69-78, https://doi.org/10.1175/BAMSD-14-00283.1.

Kirstetter, P. E., Y. Hong, J. J. Gourley, Q. Cao, and M. Schwaller, and W. Petersen, 2014: Research framework to bridge from the global precipitation measurement mission core satellite to the constellation sensors using ground-radar-based national mosaic QPE. Remote Sensing of the Terrestrial Water Cycle, Geophys. Monogr., Vol. 206, Amer. Geophys. Union, 61-79.

Kotsuki, S., K. Kurosawa, S. Otsuka, K. Terasaki, and T. Miyoshi, 2019: Global precipitation forecasts by merging extrapolationbased nowcast and numerical weather prediction with locally optimized weights. Wea. Forecasting, 34, 701-714, https:// doi.org/10.1175/WAF-D-18-0164.1.

Lader, R., J. E. Walsh, U. S. Bhatt, and P. A. Bieniek, 2017: Projections of twenty-first-century climate extremes for Alaska via dynamical downscaling and quantile mapping. J. Appl. Meteor. Climatol., 56, 2393-2409, https://doi.org/ 10.1175/JAMC-D-16-0415.1.

Lawson, B. D., and O. B. Armitage, 2008: Weather guide for the Canadian forest fire danger rating system. Tech. Rep. Natural Resources Canada, Canadian Forest Service, $87 \mathrm{pp}$.

Lewis, W. R., W. J. Steenburgh, T. I. Alcott, and J. J. Rutz, 2017: GEFS precipitation forecasts and the implications of statistical downscaling over the western United States. Wea. Forecasting, 32, 1007-1028, https://doi.org/10.1175/WAF-D-16-0179.1.

Liu, Z., D. Ostrenga, W. Teng, and S. Kempler, 2012: Tropical Rainfall Measuring Mission (TRMM) precipitation data and services for research and applications. Bull. Amer. Meteor. Soc., 93, 1317-1325, https://doi.org/10.1175/BAMS-D-11-00152.1.

Lundquist, J., M. Hughes, E. Gutmann, and S. Kapnick, 2019: Our skill in modeling mountain rain and snow is bypassing the skill of our observational networks. Bull. Amer. Meteor. Soc., 100, 2473-2490, https://doi.org/10.1175/BAMS-D-19-0001.1.

McCorkle, T. A., J. D. Horel, A. A. Jacques, and T. Alcott, 2018: Evaluating the experimental high-resolution Rapid
Refresh-Alaska modeling system using USArray pressure observations. Wea. Forecasting, 33, 933-953, https://doi.org/ 10.1175/WAF-D-17-0155.1.

Melvin, A. M., J. Murray, B. Boehlert, J. A. Martinich, L. Rennels, and T. S. Rupp, 2017: Estimating wildfire response costs in Alaska's changing climate. Climatic Change, 141, 783-795, https://doi.org/10.1007/s10584-017-1923-2.

Naud, C. M., J. Jeyaratnam, J. F. Booth, M. Zhao, and A. Gettelman, 2020: Evaluation of modeled precipitation in oceanic extratropical cyclones using IMERG. J. Climate, 33, 95-113, https:// doi.org/10.1175/JCLI-D-19-0369.1.

Nelson, B. R., O. P. Prat, D. Seo, and E. Habib, 2016: Assessment and implications of NCEP Stage IV quantitative precipitation estimates for product intercomparisons. Wea. Forecasting, 31, 371-394, https://doi.org/10.1175/WAF-D-14-00112.1.

Pickell, P. D., N. C. Coops, C. J. Ferster, C. W. Bater, K. D. Blouin, M. D. Flannigan, and J. Zhang, 2017: An early warning system to forecast the close of the spring burning window from satellite-observed greenness. Sci. Rep., 7, 14190, https://doi.org/ 10.1038/s41598-017-14730-0.

Pierce, D. W., D. R. Cayan, E. P. Maurer, J. T. Abatzoglou, and K. C. Hegewisch, 2015: Improved bias correction techniques for hydrological simulations of climate change. J. Hydrometeor., 16, 2421-2442, https://doi.org/10.1175/JHM-D-14-0236.1.

Sharafi, E., R. Steinacker, and B. Saghafian, 2016: Assessment of GPM-IMERG and other precipitation products against gauge data under different topographic and climatic conditions in Iran: Preliminary results. Remote Sens., 8, 135, https://doi.org/ $10.3390 / \mathrm{rs} 8020135$.

Shulski, M., and G. Wendler, 2007: The Climate of Alaska. University of Alaska Press, 216 pp.

Skofronick-Jackson, G., and Coauthors, 2017: The Global Precipitation Measurement (GPM) mission for science and society. Bull. Amer. Meteor. Soc., 98, 1679-1695, https://doi.org/10.1175/BAMS-D-1500306.1 .

Sungmin, O., U. Foelsche, G. Kirchengast, J. Fuchsberger, J. Tan, and W. A. Petersen, 2017: Evaluation of GPM IMERG early, late, and final rainfall estimates using WegenerNet gauge data in southeastern Austria. Hydrol. Earth Syst. Sci., 21, 6559-6572, https://doi.org/10.5194/hess-21-6559-2017.

Tang, G., Y. Ma, D. Long, L. Zhong, and Y. Hong, 2016: Evaluation of GPM day-1 IMERG and TMPA version-7 legacy products over Mainland China at multiple spatiotemporal scales. J. Hydrol., 533, 152-167, https://doi.org/10.1016/ j.jhydrol.2015.12.008.

Tian, F., S. Hou, L. Yang, H. Hu, and A. Hou, 2018: How does the evaluation of the GPM IMERG rainfall product depend on gauge density and rainfall intensity? J. Hydrometeor., 19, 339-349, https://doi.org/10.1175/JHM-D-17-0161.1.

Ziel, R. H., J. Wolken, T. St. Clair, and M. Henderson, 2015: Modeling fire growth potential by emphasizing significant growth events: Characterizing a climatology of fire growth days in Alaska's boreal forest. 11th Symp. on Fire and Forest Meteorology, Minneapolis, MN, Amer. Meteor. Soc.,1.2, https:// ams.confex.com/ams/11FIRE/webprogram/Paper272864.html.

Zubieta, R., A. Getirana, J. C. Espinoza, W. Lavado-Casimiro, and L. Aragon, 2017: Hydrological modeling of the PeruvianEcuadorian Amazon Basin using GPM-IMERG satellite-based precipitation dataset. Hydrol. Earth Syst. Sci., 21, 3543-3555, https://doi.org/10.5194/hess-21-3543-2017. 